Geopolítica(s) Revista de estudios sobre espacio y poder ISSN: 2172-3958

https://dx.doi.org/10.5209/geop.66400

\title{
El gobierno de las territorialidades transfronterizas internacionales: la experiencia latinoamericana ${ }^{1}$
}

\author{
Haroldo Dilla Alfonso ${ }^{2}$ y Karen Hansen Figueroa ${ }^{3}$
}

Recibido: 22 de septiembre de 2018 / Aceptado: 3 de octubre de 2019

Resumen. El advenimiento del régimen de acumulación postfordista, de naturaleza neoliberal, relativiza las territorialidades westfalianas y pone en jaque la noción de los límites duros protectores de los Estados-nación. Ello ha conducido a la aparición de formas específicas de "territorialidades superpuestas" - regiones y complejos urbanos transfronterizos - que colocan en un primer plano la conformación de regímenes políticos fronterizos (RPF), entendidos como el ensamblaje de instituciones, normas, procedimientos y prácticas discursivas que canalizan la interacción conflictiva de los actores públicos por recursos y valores en las territorialidades de las fronteras internacionales. Este artículo analiza la situación de los RPF en América Latina a partir de la manera en cómo los Estados perciben a sus fronteras - auspiciosas, hostiles o invisibles - teniendo como base el análisis de la información documental y académica disponible, así como los estudios de campo desarrollados por los autores en varias regiones fronterizas continentales. En particular se analizan y contrastan las experiencias nacionales Colombia, República Dominicana y Chile. El artículo concluye sobre la necesidad de miradas postwestfalianas que permitan el aprovechamiento de las sinergias transfronterizas en pos del desarrollo regional.

Palabras clave: regímenes políticos fronterizos; fronteras; regiones transfronterizas; neoliberalismo; América Latina.

\section{[en] The Government of International Cross-Border Territorialities: The Latin American Experience}

\begin{abstract}
The advent of the post-Fordist accumulation regime, of a neo-liberal nature, relativizes Westphalian territorialities and puts the notion of the hard protective limits of nation-states in check. This has led to the emergence of specific forms of "superimposed territorialities" - cross-border urban regions and complexes - that place the formation of border political regimes (BPR) in the foreground, understood as the assembly of institutions, norms, procedures and discursive practices that channel the conflicting interaction of public actors by resources and values in the territorialities of international borders. This article analyzes the situation of the BPR in Latin America based on the way in which the states perceive their borders - suspicious, hostile or invisible - based on the analysis of the available documentary and academic information, as well as the field research developed by the authors in several

\footnotetext{
1 Este artículo fue posible gracias al apoyo de CONICYT/Chile, proyectos FONDECYTs 1150812 y 1190133.

2 Instituto de Estudios Internacionales de la Universidad Arturo Prat (Chile).

E-mail: hdillaalfonso@gmail.com

3 Facultad de Ciencias Agronómicas, Universidad de Chile.

E-mail: khansenf@gmail.com
} 
continental border regions. In particular, the national experiences of Colombia, Dominican Republic and Chile are analyzed and contrasted. The article concludes on the need for post-Westfalian looks that allow the use of cross-border synergies in pursuit of regional development.

Keywords: border political regimes; borders; cross-border regions; neoliberalism; Latin America.

\section{[pt] O governo das territorialidades internacionais transfronteiriças: a experiência latino-americana}

Resumo. O advento do regime de acumulação pós-fordista, de natureza neoliberal, relativiza as territorialidades da Vestfália e põe em xeque a noção dos rígidos limites protetores dos estados-nação. Isso levou ao surgimento de formas específicas de "territorialidades sobrepostas" —regiões e complexos urbanos transfronteiriços - que colocam em primeiro plano a formação de regimes políticos fronteiriços (RPF), entendida como a assembléia de instituições, normas, procedimentos e práticas discursivas que canalizam a interação conflituante dos atores públicos por recursos e valores nas territorialidades das fronteiras internacionais. Este artigo analisa a situação da RPF na América Latina com base na maneira como os estados percebem suas fronteiras - suspeitas, hostis ou invisíveis - com base na análise das informações documentais e acadêmicas disponíveis, bem como nos estudos de campo desenvolvido pelos autores em várias regiões fronteiriças continentais. Em particular, as experiências nacionais da Colômbia, República Dominicana e Chile são analisadas e contrastadas. O artigo conclui sobre a necessidade de olhares pós-vestfalianos que permitam o uso de sinergias transfronteiriças na busca do desenvolvimento regional.

Palavras-chave: regimes políticos de fronteira; fronteiras; regiões transfronteiriças; neoliberalismo; América Latina.

Sumario. Introducción. 1. Los dilemas de los regímenes políticos fronterizos. 2. El trasfondo latinoamericano: la política versus los usos. 3. Colombia: las fronteras auspiciosas. 4. República Dominicana: la frontera hostil. 5. Chile: la "invisibilidad" de las fronteras. A modo de conclusiones: los aspectos de la institucionalidad imprescindible. Bibliografía.

Cómo citar: Dilla Alfonso, Haroldo \& Hansen Figueroa, Karen (2019) "El gobierno de las territorialidades transfronterizas internacionales: la experiencia latinoamericana". Geopolitica(s). Revista de estudios sobre espacio y poder, vol. 10, núm. 2, 259-279.

\section{Introducción}

Aunque las fronteras, como regiones circulatorias dinámicas, son datos recientes de la geografía política, la noción de que son territorialidades particulares $-\mathrm{y}$ no simplemente un límite separador - no es nueva. Siempre los límites han creado regiones orgánicas a ellos. En unos casos porque han ocurrido superposiciones territoriales resistentes a las pretensiones nacionalistas, en particular cuando los trazos limítrofes no se han compadecido de las configuraciones étnico/culturales precedentes. O porque la propia existencia del límite, con sus mecanismos institucionales de prevención del contacto (aduaneros, militares, migratorios, etc.) constituían "anillos geopolíticos interiores" (Nweihed, 1990: 302), de alto valor simbólico, que buscaban prevenir el contacto considerado superfluo e incitar a las sociedades locales a mirar hacia "los núcleos vitales" de las naciones. Pero que al mismo tiempo no podían evitar las relaciones de quienes vivían en una y otra parte. 
Se trataba de regiones liminares, usualmente explicitadas en el discurso dominante como secuelas de la pre-modernidad. Los regímenes políticos fronterizos que de aquí se derivaban eran casi exclusivamente dispositivos de control nacionalista, negadores de la transfrontericidad. En buena medida ello explica que los teóricos emblemáticos de la "fronterología" — Prescott (1987) y Nweihed (1990) — no se hubieran detenido a tratar el tema más allá de los aspectos formales de las delimitaciones y las demarcaciones.

Esta situación comenzó a cambiar aceleradamente desde el último cuarto del siglo XX. La intensificación de los movimientos de mercancías, capitales, personas e informaciones en el marco del nuevo orden neoliberal puso en jaque al sentido común nacionalista de la coincidencia inviolable de los límites de los Estados con los de su sociedad sobre territorios "naturales". Y, en consecuencia, se abrió espacio para una nueva geografía del poder que incluye las estructuras, las funciones y los desplazamientos de las zonas fronterizas.

Un signo distintivo de esta nueva geografía del poder es el surgimiento de sistemas espacio/temporales bajo jurisdicciones nacionales diferentes, lo que aquí denominaremos regiones transfronterizas (Jessop, 2001), sustentadas en dinámicas de intercambios económicos, asumidas y eventualmente construidas desde la política y organizadas en torno a ejes urbanos que se constituyen en complejos urbanos transfronterizos (Dilla, 2015). En términos heurísticos constituyen una modalidad específica de las zonas fronterizas analíticas de Sassen $(2010)^{4}$ pero se distinguen por sus densidades sociológicas, y en consecuencia por la manera como las comunidades (y sus prácticas sociales) inciden en sus desarrollos.

Obviamente, la instrumentación de las fronteras internacionales como recursos (Sohn, 2014), en contextos de mayor apertura de mercados y de proyectos integracionistas supranacionales, cambia sustancialmente sus roles, así como las formas como se ejerce el gobierno en ellas. Si las fronteras tradicionales (fordistas y westfalianas) fueron, en lo fundamental, corazas inapelables, las fronteras actuales devienen espacios dinámicos que dejan atrás la imagen del puesto fronterizo tradicional de aduaneros y soldados adustos. Y con ellos, también dejan atrás un giro binario que ha animado a la mayor parte de la producción teórica especializada: el contrapunteo entre contacto y separación.

No se trata, aclaramos, de que la contraposición entre contacto y separación sea un dilema supernumerario en cualquier región transfronteriza. Basta observar los dramas humanos que ocurren en fronteras atestadas de aspirantes a cruzarlas o los intensos programas de control de las "nuevas amenazas" para entender que ello sigue siendo un dato crucial de las fronteras contemporáneas. Sólo que resulta una expresión fenoménica en un nuevo contexto en que las fronteras se articulan como filtros para garantizar los procesos de intercambio desigual (Kearney, 2008: 81). Mezzadra \& Neilson (2013: 7) han colocado este tema a debate cuando se referían a una creciente disimilitud entre las fronteras del capital y las fronteras políticas: "Afirmamos

4 El dispositivo conceptual denominado zonas fronterizas analiticas, propuesto por Sassen (2010), da cuenta de la eclosión de nuevas dinámicas espacio/temporales en contextos de significados poco estabilizados. Y en consecuencia, en que la concepción tradicional de territorialidad y de sus jerarquías escalares es retada "[...] por las prácticas materiales, organizativas y discursivas que entran en juego cuando está en marcha el desplazamiento" (2010: 482). Aun cuando Sassen se refiere a un fenómeno de traslape espacio/temporal más general que el que nos compete, su alerta es interesante como recurso heurístico, en particular por su énfasis en la movilidad sobre la posición. 
que las fronteras son igualmente mecanismos de inclusión que seleccionan y filtran personas y diferentes formas de circulación de maneras no menos violentas que aquellas desplegadas en medidas excluyentes". Y lo hacen a través de "...la multiplicación de conexiones y desconexiones territoriales, económicas, sociales y culturales" que define la "...capacidad de jerarquización y estratificación de los bordes". Dicho en otras palabras, las fronteras devienen mecanismos de disciplinarización/normalización de la diferencia, de una modalidad de control de los individuos y de los procesos en el tiempo y en el espacio (Foucault, 2003) en aras de la reproducción de la acumulación capitalista neoliberal y de las relaciones políticas de poder que garantizan su gobernabilidad.

Con el surgimiento de estas nuevas situaciones se tornan más complejos los regímenes políticos fronterizos (RPF), entendidos para nuestros fines como el ensamblaje de instituciones, normas, discursos y procedimientos que canaliza y administra la interacción conflictiva de los actores públicos por recursos y valores en contextos de fronteras y tienen su punto nodal en el Estado, aun cuando no se reducen a él ${ }^{5}$.

Es curioso notar que, a pesar de la relevancia del asunto, los estudios sobre regímenes políticos fronterizos contemporáneos no han sido frecuentes en lo que ya constituye una voluminosa producción académica sobre fronteras, en particular en América Latina. Los pocos estudios existentes han llegado regularmente al tema desde apreciaciones generales o desde temas particulares vecinales, como es la paradiplomacia o son los pactos integracionistas.

Entre otras contribuciones individuales y colectivas sobre el tema - y sin aspiración de exhaustividad - vale la pena mencionar a Leresche \& Sáez (2001), Perkman (2003), Newman (2003), Oliveras, Durà \& Perkman (2010) y Moisio \& Paasi (2013) para el ámbito europeo; así como Machado de Oliveira (2005), Ramírez (2007), De Jesus (2007), Ovando \& Álvarez (2011), Oddone et al. (2016), Das Neves et al. (2016), Molano Rojas (2016) y Mantilla \& Chacón (2016) para la experiencia latinoamericana.

Incapaces, por razones de espacio, de producir una discusión sobre estos sugerentes productos intelectuales - lo que no impide nuestra recurrencia a ellos a lo largo de este artículo- , nos detenemos en el que probablemente constituye la aproximación teórica más coherente al tema: el artículo seminal de Leresche \& Sáez (2001). El punto central de su argumentación es la emergencia de un "nuevo paradigma territorial" al calor del surgimiento de regiones transfronterizas y las consecuentes modalidades de cooperación del mismo signo, en las que interactúan dos lógicas que denominan de afiliación y funcionales. No se trataría simplemente de una convivencia o una evolución lineal, sino de una relación conflictiva que se resuelve mediante cuotas de "despolitización" y "desideologización" respecto a los valores nacionalistas tradicionales. "Esto no significa - afirmaban - la transposición simple de un modo de toma de decisiones a otra escala; sino la aparición de un nuevo contexto cognitivo de acción pública" en que ésta última se remite a temas "[...] multi-territoriales, multi-sectoriales y multi-institucionales (Leresche \& Sáez,

\footnotetext{
$5 \quad$ El funcionamiento de cualquier RPF es inseparable de como este es aprehendido subjetivamente a partir de una serie de relatos y prácticas discursivas que guían la acción social, lo que Newman (1999: 5) definió como la “imaginación geopolítica” en un nuevo discurso geopolítico postmoderno. En este artículo circunscribimos nuestro análisis a los aspectos "duros" de la gobernabilidad fronteriza, no por preferencia metodológica alguna, sino por razones de espacio.
} 
2001: 94)”. Y desde ahí establecieron una contraposición entre una lógica política topocrática tradicional y otra adhocrática innovadora. Si la primera se basa en una “[...] relación clásica entre una autoridad política y un territorio claramente delimitado", la segunda apunta a describir una situación basada en "territorios de geometrías variables, con límites vagos y múltiples, que cambian de acuerdo a la escala sobre los cuales son tratados los problemas" (Leresche \& Sáez, 2001:95). La primera es esencialmente categórica. La segunda es eminentemente relacional. Y ambas, afirman los autores, coexisten en los espacios y en los procesos de toma decisiones.

Este artículo avanza en la discusión sobre los regímenes políticos fronterizos en América Latina, donde no ha existido - como en la experiencia europea - una voluntad política concertada - y por tanto sujeta a metodologías y programas uniformes - de superación de las fronteras nacionales. Por consiguiente, nuestro continente experimenta formas muy diferentes de estos regímenes, atenidas a historias y presentes específicos. Este artículo propone una tipología desde un ángulo específico: la manera cómo los Estados nacionales miran a sus fronteras, y, desde esa mirada, cómo se organizan los regímenes políticos fronterizos en torno a los cuales se mueven otras variables institucionales, normativas y procedimentales. Como toda propuesta de "tipos construidos", este ejercicio inevitablemente subordina la complejidad, pero la asume como punto de partida para la generación de generalizaciones, comparaciones y predicciones (Velasco, 2001).

Escoger Colombia, República Dominicana y Chile como casos de análisis para esta construcción tipológica se basa en que cada una de ellos señala un tipo específico de mirada, que llamaremos auspiciosa, hostil e invisible, respectivamente. Pero que en todos los casos indican una relación conflictiva entre el gobierno de las fronteras desde sus nuevas funciones como dispositivos de filtrado y disciplinamiento de los intercambios y la persistencia de la lógica política nacionalista.

En el análisis de los casos nacionales seleccionados, se ha prestado atención a indicadores como los tipos de menciones constitucionales, la existencia de leyes específicas fronterizas y sus contenidos, así como de otras leyes adjetivas que inciden en el tema, como es el caso, para poner un ejemplo, de las leyes orgánicas municipales. En el plano institucional se focaliza la existencia de instituciones específicas de gestión fronteriza y las adaptaciones de jure que puedan existir de instituciones nacionales. En dos de los casos analizados, República Dominicana y Chile, los autores han desarrollado diversas investigaciones de campo.

El artículo se divide en siete acápites. Tras esta introducción, un segundo acápite revisa sumariamente la producción teórica sobre el tema y avanza, desde ella, algunas ideas sobre la anatomía de los RPF. El tercero discute algunas especificidades latinoamericanas y propone los tres tipos de posicionamientos de los Estados nacionales del continente hacia sus fronteras. Los tres siguientes analizan los casos mencionados: Colombia, República Dominicana y Chile. Y finalmente en las conclusiones se realizan algunas comparaciones y se proponen algunas ideas para la gobernanza óptima de las situaciones fronterizas. De cualquier manera, las ideas que aquí exponemos tienen un tono polémico. Ello persigue un objetivo vital para el trabajo académico: incentivar el debate como herramienta epistemológica, calistenia inseparable de aquello que Morin (2000: 59) llamaba "el derecho a la reflexión (en contraposición a) la confrontación ciega de los hechos o la verificación testaruda de hipótesis fútiles". 


\section{Los dilemas de los regímenes políticos fronterizos}

Los RPF son arreglos institucionales complejos. Constituyen "regímenes de autoridad territorial" específicos, articulados sobre "territorialidades superpuestas" (Agnew \& Oslender, 2010: 193) en que las disputas por el ejercicio de la soberanía que erosionan las capacidades del Estado nacional no solamente ocurren en relación con los campos no-estatales (mercado, sociedad civil organizada, comunidades), sino también en relación con otros Estados.

Ello no significa la invalidación de los Estados nacionales como factores de soberanía en las fronteras, que siguen siendo medularmente westfalianas - no hay regímenes políticos transfronterizos, sino a lo sumo vasos comunicantes entre los regímenes de las franjas fronterizas nacionales-, pero sí denota su creciente incapacidad para explicar per se los procesos de territorialización que ocurren en sus jurisdicciones. La relación dialéctica implícita en la tríada de la construcción espacial que Lefebvre (2013) remitía a lo concebido, lo percibido y lo vivido se muestra aquí de manera traslapada. Donnan \& Wilson (1999: 57), en una obra seminal, remitían esta complejidad al hecho de que los poderes tradicionales eran "compartidos, diluidos, contaminados y dispersados" en múltiples flujos que delineaban pertenencias e identidades. Nociones claves de la gobernabilidad y la política (como orden, acatamiento, normas y poder) se realizan en lo difuso. Todo lo cual confunde a los actores centrales - deseosos de un orden lineal y binario - pero es perfectamente llevadero para los rayanos acostumbrados a desarrollar sus vidas en estos complejos vericuetos.

En términos analíticos, todo régimen político fronterizo - asumiéndolo como espacio de acción pública no limitado al Estado, pero determinado por éste- posee al menos tres ensamblajes funcionales en cada uno de los cuales interactúan instituciones, normas y procedimientos:

1) En primer lugar, tenemos aquellos ensamblajes que garantizan la administración de las franjas fronterizas como componentes del territorio nacional. En términos institucionales aquí se ubican todas las organizaciones desconcentradas o descentralizadas que a nivel nacionales garantizan la administración de los asuntos públicos: oficinas desconcentradas de ministerios, gobiernos locales o instituciones específicas formadas al calor de programas desarrollistas.

Por definición, el funcionamiento de estas instituciones — particularmente en regímenes centralizados - no se distingue fundamentalmente de las que existen en otros territorios subnacionales. En la práctica, pueden asumir funciones ad hoc coordinadas transfronterizas (por ejemplo, en caso de emergencias epidemiológicas) o que se derivan de esta condición, como es el caso del sistema de educación básica cuando tiene que afrontar una fuerte presencia de alumnos inmigrantes. Aunque en casos excepcionales estas acciones puedan ser incorporadas formalmente a los protocolos de procedimientos, regularmente ocurren al margen de la normatividad, por lo que pueden ser consideradas como desviaciones que pueden implicar alianzas innovadoras con la sociedad civil.

2) Una segunda franja institucional se refiere a organizaciones y normas propiamente de control fronterizo, que solo existen en situaciones de esta 
naturaleza (terrestres, portuarias, aeroportuarias). Incluyen aduanas, oficinas de inmigración y control zoo-fito-sanitario, así como cuerpos de seguridad especializados, a las que, en fronteras terrestres, se agregan contingentes militares. Estas son las típicas instituciones de las fronteras duras westfalianas, que en la medida en que los peligros dejan de ser visualizados en los Estados vecinos y se centran en otros factores de amenazas (como narcotráfico, terrorismo o pandemias) también implican espacios de concertación. Un ejemplo cada vez más usual de estas adaptaciones son los sistemas de controles integrados en los pasos fronterizos sudamericanos. En casos extremos, estas instituciones pueden llevar las fronteras a lo que Rosière \& Jones (2012) calificaban como teichopolítica, niveles máximos de tensión en sus funciones antes descriptas de control y normalización. No menos relevante es la extensión de prácticas de corrupción que rellenan la brecha existente entre las normas y el funcionamiento posible. Es posible encontrar grupos nacionalistas de la sociedad civil que pueden enrolarse en las acciones de apoyo en esta dirección, con más valor simbólico que práctico.

3) Finalmente, en las franjas fronterizas aparecen instituciones cuyas finalidades son viabilizar los contactos e intercambios transfronterizos y que sirven de canales o plataformas para la práctica de lo que hoy se discute como "paradiplomacia". Cuando los gobiernos municipales y regionales tienen cuotas significativas de autonomía y vocación transfronteriza, devienen actores destacados de este tipo, pero aquí resulta decisiva la participación de organizaciones de la sociedad civil en ocasiones con el apoyo de la cooperación internacional. Dos casos usuales en América del Sur son los Comités de Integración y Desarrollo Fronterizo (Valenciano, 1990) y las Zonas de Integración Fronteriza (Ramírez, 2007).

Vale la pena destacar que en cualquiera de estos ensamblajes funcionales pueden producirse prácticas de relaciones transfronterizas remisibles a la paradiplomacia ${ }^{6}$. Como antes decíamos, ello puede ocurrir, por ejemplo, cuando las autoridades nacionales localizadas dialogan sobre manejos de fronteras (comercio o controles migratorios) y adoptan procedimientos cooperados, pero es indudable que sus despliegues más consistentes ocurren desde los actores propiamente locales. En fronteras marcadas por la informalidad y las debilidades institucionales, buena parte de estos vínculos transfronterizos se incuban y modelan desde las prácticas sociales, que devienen ejes organizadores relacionales.

\section{El trasfondo latinoamericano: la política versus los usos}

Durante el siglo XIX y buena parte del siglo pasado los regímenes fronterizos latinoamericanos daban cuenta de fronteras en que los intercambios formales se

6 Cornago (2016) ha remitido la paradiplomacia al involucramiento de los gobiernos locales y otros actores subnacionales - públicos y privados - en las relaciones internacionales con el propósito de promover sus agendas en esos contextos. Ello habla de un tema atractivo pero complicado que ha estado experimentando una cierta inflación conceptual. Dada esta complejidad — cuya discusión rebasa nuestro espacio— preferimos aquí hablar aquí de activismo transfronterizo como fenómeno político específico de concertación regional. 
reducían a contactos eventuales, mientras que en el ámbito cotidiano los contactos funcionaban como áreas "grises" o "negras", invisibilizadas o sometidas a escrutinios represivos. Como ha puntualizado Baud (2000), la demarcación, colonización y habilitación institucional de las zonas (trans)fronterizas derivó de apremios geopolíticos que no se compadecían de las múltiples relaciones informales consuetudinarias distantes de la política formal. No obstante esta "inorganicidad" limítrofe, desde fines del siglo XIX han sido pocos los desacuerdos que han desembocado en conflictos armados, entre otras razones, por la existencia de mecanismos de mediación efectivos (Domínguez, 2003).

Desde la última década del pasado siglo — en el marco de los encauzamientos neoliberales de la política continental y de los proyectos de regionalismo abiertolas fronteras y sus regiones aledañas han experimentado la intensificación de los intercambios formales e informales, la entrada en escena de diversas escalas y agentes y la inevitable complejización de los entramados normativos e institucionales que intentan gobernarlas. Aunque ello ha significado en todos los lugares una suerte de disonancia para regímenes basados en una cosmovisión westfaliana de la política, no ha ocurrido de igual manera en toda la geografía continental. De manera preliminar y operativa para los fines de nuestra discusión, pudiéramos remitir esta diversidad multicontextual a tres tipos, a sabiendas que, como siempre ocurre, existen mezclas y desplazamientos eventuales en una u otra dirección:

1) Los Estados que han logrado avanzar hacia una perspectiva desarrollista que toma en cuenta la relación transfronteriza como condición para ella, y en consecuencia asumen discursos y prácticas integracionistas. Es un tipo de posicionamiento que gana espacio en los textos constitucionales y legales, así como en las construcciones institucionales. Como antes anotaba, se trata de un tipo de proyección en algunas ocasiones arropados por proyectos integracionistas auspiciosos — como sucede con Colombia y Perú, miembros de la actual Comunidad Andina de Naciones $(\mathrm{CAN})^{7}$ - , pero también a políticas nacionales específicas, como sucede en los casos de Brasil y Uruguay (Oddone \& Galantini, 2015), y Nicaragua (Mantilla \& Chacón, 2016). El caso paradigmático es las zonas de integración fronteriza implementadas por la Comunidad Andina de Naciones.

2) El otro extremo de esta tríada está constituida por los Estados que mantienen una actitud hostil hacia sus fronteras, percibiéndolas como amenazas a valores esenciales nacionales, y en consecuencia se esmeran en implementar políticas de separación. Resulta de jure un posicionamiento remanente de otros tiempos, pero también puede actualizarse por coyunturas políticas. No les distingue un grado específico de densidad institucional o normativa, lo

\footnotetext{
En realidad, el único proyecto regional integracionista que ha desarrollado una perspectiva transfronteriza ha sido la CAN. Desde los Acuerdos de Cartagena en 1969, el proyecto integracionista andino ha mirado a las fronteras. En 1999 se dio un paso adelante con la promulgación de un primer manojo de lineamientos agrupados en el documento "Política comunitaria de Integración y Desarrollo Fronterizo" y la constitución de un grupo de alto nivel. En 2001 se abrió el proceso para la creación de las Zonas de Integración Fronteriza (ZIF) y de los Centros Binacionales de Atención en Fronteras". Cualesquiera que sean las valoraciones sobre sus resultados, es indudablemente un valor agregado de este proyecto (Ramírez, 2007). Las menciones usuales en otros proyectos regionales — como es el caso del MERCOSUR - han tomado nota del asunto tardíamente, y cuando lo hacen apuntan a la frontera como lugar de paso de mercancías y personas, es decir, como "no lugares".
} 
cual puede variar de un caso a otro, sino la manera como la frontera es conceptualizada explícita o implícitamente. Son los casos de República Dominicana, Costa Rica (Mantilla \& Chacón, 2016) y Venezuela desde su abandono de la CAN.

3) Finalmente, un tercer tipo de posicionamiento implica a los Estados que mantienen una política indiferente hacia sus fronteras en cuanto comunidades, llegando en ocasiones a extremos de omisión discursiva total. No se trata de que no controlen - obviamente lo hacen-y en este sentido son duramente westfalianos. Pero no es la hostilidad lo que guía sus políticas, sino la invisibilidad: omisiones constitucionales y normativas, débil institucionalidad y la inexistencia de políticas específicas. Tres casos paradigmáticos son Haití, Argentina y Chile. Lo más usual es que estos países, que afrontan situaciones fronterizas diversas, traten estos asuntos como partes de las agendas bilaterales.

\section{Colombia: las fronteras auspiciosas}

En términos formales, Colombia es uno de los países latinoamericanos que más ha avanzado hacia una formulación que Mantilla \& Chacón (2016) llaman integracionista y que aquí preferimos señalizar como de tono transfronterizo.

Colombia posee límites terrestres con cinco países (Brasil, Venezuela, Perú, Ecuador y Panamá) con situaciones económicas, políticas y culturales diferentes, lo que ha configurado una multiplicidad de situaciones limítrofes. Al mismo tiempo, los 13 departamentos y 17 municipios limítrofes combinan bajos niveles de desarro110 - en comparación con los promedios nacionales - con las afectaciones dadas por el narcotráfico y los conflictos bélicos que han tenido lugar en el país, todo lo cual ha sido destacado por los organismos estatales como una prioridad por sus implicaciones geopolíticas (Cancillería, 2013). Y finalmente, al menos tres de los países vecinos comparten (o han compartido) con Colombia membresías en la Comunidad Andina de Naciones, como decíamos, el pacto integracionista que indudablemente más atención — y por más tiempo — ha dedicado a la creación de espacios fronterizos integrados.

La Constitución de la República de Colombia (1991) enfatiza explícitamente el compromiso estatal con el desarrollo fronterizo, en el marco de los proyectos integracionistas regionales. Estipula la necesidad de fomentar la cooperación internacional en casos de manejo de recursos medioambientales en la frontera (art. 80) y el respeto de los "pueblos indígenas que comparten territorios fronterizos" (art. 96). Por otro lado, otorga atribuciones a los departamentos y municipios ubicados en límites fronterizos para trabajar de forma autónoma con los países vecinos en "programas de cooperación e integración, dirigidos a fomentar el desarrollo comunitario, la prestación de servicios públicos y la preservación del medio ambiente" (art. 289). Las principales atribuciones para el desarrollo de las fronteras residen la Dirección para el Desarrollo y la Integración Fronteriza, ubicada en la cancillería.

Asimismo, Colombia cuenta con una Ley de Fronteras (Congreso de Colombia, 1995), la que establece un "régimen especial para las zonas de frontera". La ley declara nueve objetivos. Algunos de estos objetivos son consustanciales con una visión tradicional geopolítica de la frontera (coordinación de acciones de seguridad, 
infraestructura para garantizar conectividad, desarrollo hacia adentro, etc.), pero otros adelantan una visión transfronteriza poco usual en el momento de su promulgación. En particular el segundo objetivo declara como prioridad el "fortalecimiento de los procesos de integración y cooperación que adelanta Colombia con los países vecinos y [la] eliminación de los obstáculos y barreras artificiales que impiden la interacción natural de las comunidades fronterizas, inspirados en criterios de reciprocidad", además de sostener una disposición a "prestar los servicios necesarios para la integración fronteriza" y buscar la "cooperación con los países vecinos y sus instituciones" (art. 2).

A partir de una definición socioeconómica de la zona fronteriza (municipios colindantes o con fuerte relación transfronteriza), la ley consagra una singularidad novedosa tomada de los anaqueles de la CAN: la creación de una serie de figuras territoriales, como son las Unidades Especiales de Desarrollo Fronterizo y las Zonas de Integración Fronteriza, correspondientes a niveles político-administrativos diferentes, tales como municipios y departamentos. Pero que comparten metas y funciones en la dirección de "[...] crear condiciones especiales para el desarrollo económico y social mediante la facilitación de la integración con las comunidades fronterizas de los países vecinos, el establecimiento de las actividades productivas, el intercambio de bienes y servicios, y la libre circulación de personas y vehículos" (art 4., inciso B). Esta idea de la regionalización fue nuevamente asumida en la ley 1454 de 2011 , sobre planificación, que autoriza a los municipios fronterizos a crear regiones mediante la asociación de varios de ellos.

Obviamente, sería ingenuo tomar la legislación al pie de la letra y creer que las instituciones son testimonios irrefutables de avances en todos los sentidos. La realidad de las políticas estatales colombianas hacia las fronteras ha sido sometida a severas críticas por diversos analistas, los que han coincidido en argumentar la alta centralización que ha caracterizado los procesos de toma de decisiones, un sello inevitable de la naturaleza westfaliana del Estado. Como han apuntado Mantilla \& Chacón (2016), ha prevalecido un enfoque centralista que ha ahogado los mejores propósitos de los actores locales. Por su parte, Hurtado \& Aponte critican "una institucionalidad [...] precaria, ineficiente y limitada, así como excluyente en términos de gestión, diseño e implementación" (2017: 84), lo que plantea una "[...] cierta descoordinación entre la evolución legislativa y su efectiva implementación local" (2017: 71). Al referirse a la frontera colombo-venezolana —en particular a lo que consistió en una suerte de caso-prueba del integracionismo: el eje Cúcuta-TáchiraRamírez detectó una desventajosa "[...] superposición entre las relaciones transfronterizas espontáneas [...] y los acuerdos intergubernamentales hechos en ejercicio de la soberanía nacional" todo lo cual plantea la necesidad de "[...] modificaciones centrales en la relación de lo local con lo nacional, lo subregional y lo regional" (2007: 88-89).

No obstante, es innegable que estamos aquí en presencia de uno de los procesos más integrales de construcción institucional de las fronteras en este continente, al menos en tres sentidos:

- El Estado colombiano asume positivamente a la frontera como región específica en un cuerpo normativo e institucional relativamente integral.

- Reconoce a los actores locales fronterizos como sujetos de derecho y con espacios propios de actuación. 
- Entiende a la frontera nacional como inseparable de una situación transfronteriza, y en consecuencia sus diseños trazan puentes explícitos para el relacionamiento en ese sentido.

Se trata de un equilibrio muy inestable, que habla de políticas entrampadas en el entrecruzamiento de lógicas diferentes y contradictorias desde las soberanías, la acumulación y las vidas cotidianas. Y aunque desde estas últimas es previsible encontrar una mejor disposición integracionista, estimulada por historias de intercambios y contactos, también aquí aflora la cultura política nacionalista:

Las poblaciones de la frontera siguen hablando de su integración espontánea cuando están frente a las capitales, pero hacen uso del nacionalismo [...] frente a los problemas que comparten con sus vecinos. Sigue primando la crítica generalizada y sin propuestas, la informalidad de las relaciones, el mero aprovechamiento de las ventajas que por el diferencial de cambios se suscitan a uno $u$ otro lado de la frontera, la presión política frente a asuntos particulares más que la relación con problemas colectivos, y la mirada de corto plazo y coyuntural (Vieira \& Ramírez, 2004: 7).

\section{República Dominicana: la frontera hostil}

En las antípodas de esta experiencia se ubica República Dominicana. Este país comparte unos $300 \mathrm{~km}$ de frontera con Haití, y constituye un caso poco usual a nivel planetario de una isla regida por más de una soberanía. Es probablemente la nación latinoamericana que menos ha avanzado en la superación de una visión netamente geopolítica - la frontera como límite y la distancia como virtud-, a pesar de los marcados intereses económicos que tiene con su vecina occidental. Tanto la normativa como la institucionalidad dominicana se ocupan intensamente de la frontera. Pero lo hacen de manera vergonzante, generando una suerte de agolpamiento de disposiciones y leyes totalmente disfuncional. En este sentido es importante entender dos cuestiones.

En primer lugar, desde el período 1929-1936 en que se negoció el tratado de límites (fundamentalmente de delimitación y demarcación) no ha existido nada parecido a un acuerdo binacional sobre el manejo de las fronteras, como sobre ningún otro tema relevante a excepción de los acuerdos puntuales - vigentes hasta los 1980s - para la contratación de braceros haitianos para la industria azucarera radicada en República Dominicana. Tampoco existe un acuerdo integracionista que incluya a ambos países y que hubiera trazado puentes. Y en este sentido habría que apuntar que aún cuando hubiese existido una voluntad concertacionista de la parte dominicana - la cual solo se ha expresado puntual y débilmente- el rasgo característico del Estado haitiano ha sido su extrema debilidad e incapacidad para ejercer un control sobre su jurisdicción, y desde aquí una perspectiva que antes definíamos como indiferente. En consecuencia, excepto en algunos lugares de relevancia fiscal (como los cuatro pasos fronterizos mayores), la franja fronteriza haitiana resulta un páramo institucional.

La segunda cuestión a tomar en cuenta es la configuración ideológica de la frontera. Desde la primera mitad del siglo XX, cuando la República Dominicana inició 
la configuración de un Estado centralizado, el tema haitiano pasó a ser una referencia identitaria antitética. De hecho, un año después del acuerdo de límites de 1936, se produjo una horrible matanza de haitianos y dominico-haitianos por parte de la recién estrenada dictadura de Rafael L. Trujillo, y el borde fue cerrado para todos los fines a excepción de un escuálido tráfico comercial y del paso anual - controlado por los militares de ambos lados- de los contingentes de braceros migrantes. Ello fue acompañado de un proceso de inversiones públicas en la zona y de incentivos para atraer población a una franja que había quedado virtualmente despoblada. Es lo que se ha denominado la "dominicanización de la frontera" (Mateo, 2004). La denominación dada a la zona - "el confín de la patria"- le otorgaba un sentido de gueto, más allá del cual se encontraba el otro antitético, la anti-patria.

Obviamente la frontera que hoy conocemos es diferente a la que construyó la dictadura. Existen mercados compartidos y numerosos cruces de personas, interacciones socioculturales e incluso prácticas de activismo que cruzan los bordes, todo lo cual configura el surgimiento de regiones transfronterizas. De igual manera, el capital dominicano transnacionalizado ha tomado nota de las ventajas comparativas haitianas (bajos salarios, desregulación ambiental, débil presión fiscal, acceso privilegiado a mercados desde su condición de pobreza, etc.) y ha comenzado a establecer empresas maquiladoras de ensamblaje industrial en el mismo borde. Pero ninguna de estas conveniencias ha retado la rémora de los prejuicios ideológicos e históricos de ambas partes, y que ahora se incorpora como apuntalamientos de la relación desigual (Dilla, 2016). Las actividades comerciales, los encadenamientos productivos, los contactos culturales y los fuertes procesos de movilidad humana que cruzan por la frontera o se asientan temporalmente en ella, transcurren bajo el manto ideológico del racismo antihaitiano.

Como antes se anotaba, la hostilidad hacia la frontera no significa una desatención institucional y normativa, sino al contrario. Además de las instituciones regulares del sistema administrativo dominicano y de aquellas otras dirigidas al control de los bordes, la frontera dominicana es atendida por cuatro instituciones especializadas (De Jesús, 2007):

- El Consejo Nacional de Fronteras, creado en 1967 sin funciones especificadas y radicado en la cancillería. Se dedica a ejecutar acciones de afirmación de la simbología nacional, tales como la construcción de plazoletas, estatuas de próceres, donación de banderas, etc.

- La Dirección General de Desarrollo Fronterizo, creada en 2000, mediante decreto, sin funciones especificadas, y que radica como un departamento de la presidencia. Posee oficinas en toda la franja y varios centenares de empleados, y sus principales acciones han sido intervenciones puntuales en pequeñas obras sociales y económicas.

- El Consejo de Coordinación de la Zona Especial de Desarrollo Fronterizo, creado mediante decreto en 2001, y reguladas sus funciones en 2005. Está adscrito al Ministerio de Industria y Comercio. Es una pequeña oficina cuya función principal es coordinar acciones de desarrollo que incluyen al sector privado y administrar la adjudicación de incentivos inversionistas al calor de una ley de fomento nacionalista, denominada 28-01.

- Finalmente, la Dirección General de Promoción de las Comunidades Fronterizas — creada en 1979 — que pertenece a las fuerzas armadas, y su función 
es apoyar el desarrollo de la frontera mediante pequeñas obras ejecutadas en lugares de alta sensibilidad geopolítica.

De igual manera, existe un organismo paramilitar, el Cuerpo Especializado de Seguridad Fronteriza (CESFRONT), dedicado exclusivamente a la franja, pero que no omite una fuerte presencia militar ordinaria en lo que constituye una de las fronteras más militarizadas de este continente. Pero, sintomáticamente, no existe nada parecido a un régimen municipal fronterizo que facilite ciertas capacidades a los municipios - entidades desposeídas en un sistema político muy centralizado - ni a ningún otro espacio formal transfronterizo de gobernanza.

En términos normativos, las constituciones dominicanas siempre han prestado atención a la frontera, pero como límites que separan y protegen. De hecho, la frontera ha sido históricamente la única región nacional que es mencionada como objeto de desarrollo. La Constitución de la República Dominicana (2010) habla expresamente en su sección II de un "régimen de seguridad y desarrollo fronterizo" que da cuenta del interés nacional por "[...] la seguridad, el desarrollo económico, social y turístico de la Zona Fronteriza, su integración vial, comunicacional y productiva, así como la difusión de los valores patrios y culturales del pueblo dominicano". Aunque no existe una ley propiamente de fronteras, se han promulgado leyes, decretos y reglamentos dirigidos a ella, pero siempre tratándole como parte del cuerpo nacional y obligada a mirar hacia él. En los espacios institucionales que tratan las relaciones transfronterizas (por ejemplo, en la comisión mixta binacional adscripta a la cancillería - existe otra similar en Haití-) el tema fronterizo es siempre una parte marginal de una agenda que prioriza temas más redituables (comercio, inversiones, migraciones, etc.) y siempre avanza muy lentamente asediada por la burocracia, los sobresaltos en las relaciones bilaterales y la desidia política.

Ello ha motivado a De Jesús (2007: 180) a caracterizarle como un sistema "que no responde a los procesos y necesidades que se verifican en los principales perfiles de la frontera". Pero que no omite su funcionalidad para la reproducción de un orden xenófobo y excluyente que ha convertido a Haití no solo en un pivote clave de la acumulación capitalista en República Dominicana, sino también de la reproducción ideológica del propio sistema político.

Obviamente, el resultado de esta configuración arcaica no ha sido el cierre de los contactos, sino la realización de éstos a través de agujeros de facto, que agregan inseguridad y vulnerabilizan a los "otros" que se pretende negar. Ello genera un desfase entre las restricciones formales y las dinámicas reales con las consiguientes distorsiones insalvables de las prácticas respecto a los procedimientos consagrados. Ambas partes de la frontera sobreviven gracias a los contactos mutuos, y estos no se detienen ante la rigidez de las normas. Por consiguiente, esta frontera funciona con desviaciones fundamentales de las prácticas respecto a los procedimientos legales. En ocasiones esto puede producir resultados altruistas, como son los casos de múltiples proyectos de colaboración entre actores locales dominicanos y haitianos, con frecuencia con apoyo de la cooperación internacional, cuya manifestación más relevante fue la formación de un Comité Intermunicipal Transfronterizo entre 2008 y 2013 (Dilla, 2016). Pero también conduce a situaciones negativas, siempre lubricadas por niveles muy altos de corrupción. 


\section{Chile: la "invisibilidad" de las fronteras}

A diferencia de Colombia — que ha optado por una incorporación de la cuestión de las fronteras a su normativa desde una perspectiva transfronteriza - o de República Dominicana — que ha mantenido una posición conservadora de negación funcional y de abigarramiento institucional - el Estado chileno ha optado por la "invisibilidad" del asunto. Y lo ha hecho históricamente.

Aunque la sociedad chilena ha atravesado por momentos político/ideológicos muy disímiles (en la última parte del siglo XX, por ejemplo, transitó por la experiencia populista de Carlos Ibáñez, el programa reformista de Eduardo Frei, la propuesta socialista de Salvador Allende o la dictadura neoliberal de Augusto Pinochet) no es posible hallar diferencias sustanciales en la manera como estos regímenes (no) miraron a la frontera. Existieron cambios dependiendo de la existencia de situaciones conflictivas o perspectivas de desarrollo. Los habitantes de la región fronteriza de Arica, por ejemplo, recuerdan con agrado los tiempos en que el General Carlos Ibáñez (1952-1958) instrumentó un modelo industrializador mercado-internista con cuantiosas inversiones públicas, al mismo tiempo que guardan poca estima por la gestión de la dictadura militar desde 1973, cuando Arica fue penalizada con el desmantelamiento económico y el conflicto geopolítico. Pero en lo que nos concierne en este artículo, ambas políticas estuvieron dirigidas a negar la frontera como realidad sociocultural, sea fomentando los vínculos económicos con el mercado interno chileno o abandonando la zona a los designios estrictamente geopolíticos.

Las constituciones políticas chilenas han sido omisas respecto a las fronteras. La constitución vigente (1980) no las menciona en ninguno de sus artículos, omitiendo por completo su definición y su concepción acerca del trato que éstas deben recibir y cuál es la importancia que tienen para el Estado. De igual manera, no existe una ley de fronteras, y la legislación específica de la que pudiera esperarse algún tratamiento privilegiado del tema, les excluye. Para hacer un ejemplo, la ley Orgánica Municipal (18.695), emitida en julio de 2006, solo menciona la palabra "frontera" una vez para indicar que, en los municipios limítrofes, los consejos comunales deben incluir a las autoridades encargadas del control en los bordes

Estas limitaciones han incidido en que no exista desde el Estado una perspectiva de desarrollo de las zonas fronterizas basada en las dinámicas que esta situación genera, sino de acciones que dependen de la situación de las relaciones bilaterales. De manera que en este punto las políticas chilenas coinciden con las dominicanas en cuanto a la implementación de programas de fomento que priorizan la mirada hacia adentro, y en consecuencia el desaprovechamiento de los probables efectos sinérgicos de las dinámicas transfronterizas. Un ejemplo de ello son los programas de inversiones que se realizan desde la perspectiva de "las zonas extremas" y que han beneficiado a una parte de las zonas fronterizas nacionales. La definición de "zonas extremas" implica una noción de frontera, pero no de frontera internacional, sino de frontera interna. Es decir, de espacios distanciados, pero a integrar al cuerpo nacional a partir del fomento económico y la socialización cultural. Siguiendo la definición oficial, se trataría en lo fundamental de:

Un territorio geográficamente aislado, con bajo nivel de accesibilidad, con escasa población y alta dispersión de ésta, en el que se observa una baja presencia y cobertura de servicios básicos y públicos, que a consecuencia de estos factores se 
encuentra en una situación de desventaja y desigualdad social respecto del desarrollo del país (SUBDERE, 2013: 4).

En este contexto, el dato positivo es la paulatina actualización de conceptos y políticas al calor de los procesos de mundialización y regionalización que implican nuevas funcionalidades de las fronteras y de las que Chile no puede sustraerse. Un ejemplo de ello es la creación de la Dirección de Fronteras y Límites (DIFROL) de la cancillería, la que expresa la contradicción entre la doxa westfaliana y los reclamos transfronterizos de los tiempos. La DIFROL fue creada por ley en 1966 bajo el gobierno reformista de Eduardo Frei Montalva (1964-1970), el mismo gobierno que oficializó la adherencia de Chile al Pacto Andino. Al definir las funciones de la DIFROL, el presidente Frei fue enfático en caracterizar la nueva institución como una entidad dirigida a manejar cuestiones de límites inamovibles:

Tender todo lo que se refiera a los límites internacionales de Chile y a sus fronteras terrestres, marítimas y aéreas, como asimismo al Territorio Chileno Antártico debiendo por lo tanto intervenir en la determinación, demarcación y conservación de esos límites; proponer las medidas que deban adoptarse en relación con ellos y con la política territorial en las regiones fronterizas; dar cumplimiento a las órdenes o instrucciones que el Presidente de la República o el Ministro de Relaciones Exteriores impartan sobre la forma de protegerlos y de orientar el régimen en todos sus más variados aspectos aplicables en ellos, incluso en cuanto a la intervención del Estado en la defensa de los litigios o juicios ante árbitros o tribunales arbitrales o de cualquier naturaleza que se refieran a asuntos de fronteras y/o límites chilenos como asimismo (Frei Montalva, 1966, online).

Curiosamente, esta definición dada hace medio siglo es fundamentalmente la misma que hoy puede encontrarse en la página web de la institución:

Preservar y fortalecer la integridad territorial del País, asesorando profesional y técnicamente al Supremo Gobierno y participando en la celebración y aplicación de Tratados, en la negociación de Convenios, así como en los Foros y en las materias relacionadas con los Límites Internacionales de Chile y las Políticas de Integración Física, Vecinal y Regional, a través del Ministerio de Relaciones Exteriores (MINREL, 2017, online).

Pero más allá de sus magras definiciones programáticas, la DIFROL tiene en su haber la pieza institucional más avanzada del entramado fronterizo chileno: los ya mencionados Comités de Integración y Desarrollo Fronterizo (CIDF). Estos comités han tenido funcionamientos regulares en los bordes compartidos con Argentina y Perú, y hasta 2011 — cuando fueron sobrepasados por el conflicto bilateral— también con Bolivia. Fueron innovaciones interesadas en incentivar el intercambio comercial, la integración vial y la cooperación energética, casi siempre en términos muy pragmáticos. Pero ante la carencia de una perspectiva integral, los resultados prácticos han sido modestos, lo cual ha sido explicado por Ovando \& Álvarez (2010: 98): 
Además de la interacción económica a través de la frontera, no se advierte una interacción política en los distintos niveles gubernamentales que incluya la complejidad de las dinámicas transfronterizas. Mientras las actividades comerciales y de desarrollo están provocando incipientes cambios en las estrategias, regulaciones e iniciativas concernientes al régimen fronterizo, junto con la emergencia de nuevas identidades, todavía hay cuestiones pendientes para consolidar dicho régimen a un nivel político-gubernamental.

En la misma medida en que han resultado instituciones estatales y centralizadas, el funcionamiento de los CIDF con los tres países que comparten fronteras con Chile ha dependido más de las relaciones bilaterales que se cocinan desde las respectivas cancillerías que de las motivaciones y dinámicas locales. Ello explica, por ejemplo, que el comité no funcione con Bolivia, que lo haga en permanente déficit con Perú (Álvarez, 2019; Dilla \& Hansen, 2019) y que muestre sus mejores expedientes cuando entran en contacto lo que Silva \& Morán (2010) llaman los entes territoriales fronterizos chileno/argentinos.

Explicar las razones de este tipo de comportamiento a nivel continental rebasa los alcances de este artículo. En el caso específico de Chile existe una condicionante histórica que no puede ser soslayada: las fronteras chilenas han sido el resultado traumático de una historia de enfrentamientos, en particular en el Norte Grande pero también extensivo a la relación con Argentina. En consecuencia, el país se ha visto a sí mismo como un Estado-Isla marcado por "[...] la rivalidad histórica chileno/vecinal" (Leyton, 2011: 15-16). Y la clase política ha priorizado - como afirma Santis (1998: 138) — nociones extraídas de los anaqueles ratzelianos. De igual manera debe tomarse en cuenta que en ningún caso la relación chileno-vecinal ha estado mediada por acuerdos integracionistas que motiven perspectivas transfronterizas. La inamovilidad de los límites, más que el desarrollo transfronterizo es el principio rector de las políticas estatales. El presidente Frei (1966), en el mismo discurso en que proclamaba la creación de la DIFROL, era concluyente:

Porque es evidente - afirmaba - que para el planteamiento de cualquier asunto limítrofe actual nuestro ha de darse por establecido en forma inamovible que no existe de parte de Chile como de cualquier Estado vecino, la voluntad de modificar sus fronteras o límites en virtud de nuevos convenios o tratados y en consideración a factores políticos, ideológicos, jurídicos o de otro orden. Sólo hay la voluntad de materializar hasta dónde alcanza la soberanía de cada país, estimando que los límites entre ellos fueron ya establecidos por tratados o convenios, e incluso por fallos, en vigor.

\section{A modo de conclusiones: los aspectos de la institucionalidad imprescindible}

Al calor de las dinámicas económicas neoliberales, las fronteras latinoamericanas experimentan desplazamientos funcionales cruciales. Ellos van desde la administración de la estricta relación contacto/separación a la normalización y disciplinarización - en los términos antes explicados - de los flujos de capitales, mercancías, personas e informaciones, sea como estrategias de acumulación o como prácticas sociales de sobrevivencia. Ello condiciona la aparición de nuevas regiones 
transfronterizas entendidas como territorialidades superpuestas (Agnew \& Oslender, 2010) e implican una mayor complejidad de los regímenes políticos fronterizos, entre otras razones porque toman nota de esta realidad, pero desde las particularidades sociohistóricas de cada frontera.

Al efecto se proponen tres situaciones de RPF, definidas a partir de la manera como los estados nacionales miran y administran sus fronteras. Estas situaciones van desde un tipo desarrollista que argumenta con criterios transfronterizos (Colombia), hasta otros que siguen mirando a la frontera como trincheras nacionalistas (República Dominicana), o que le prodigan miradas descuidadas que omiten legislaciones e instituciones especializadas, como es el caso de Chile. En todos los casos han sido miradas desde el nacionalismo y la centralización, lo que ha limitado los efectos positivos incluso de los proyectos más avanzados.

Las razones de estas diferencias dependen de muchos factores. Aunque la diferencia/similitud cultural es siempre un elemento discursivo, no parece que sea efectivamente un factor determinante en la voluntad de las élites políticas para generar acciones de integración. Más relevante pudiera ser la manera en que esas fronteras han sido construidas ideológicamente, los niveles y tipos de concertación de los estados nacionales involucrados y el grado y tipo de interpenetración económica que impregna las relaciones de un sentido utilitario. Remitiendo esta última a la posibilidad de sobrepasar lo que Sohn (2014) llamaba una relación "geoeconómica" instrumental basada en la explotación simple de ganancias diferenciales a otra de tipo "territorial" con planos deliberados de convergencia multidimensional. También habría que destacar la existencia de pactos integracionistas multinacionales que incluyan estos temas en sus agendas, que han demostrado ser un elemento clave, como ha sucedido con la Comunidad Andina de Naciones.

Desde este balance no es difícil imaginar condiciones imprescindibles para conseguir regímenes fronterizos capaces de proveer una gobernanza democrática y adecuada a los requerimientos que plantea el desarrollo regional en estas condiciones. Es decir, regímenes políticos que den cuenta de la multidimensionalidad de las regiones transfronterizas, que no pueden ser reducidas a reestructuraciones territoriales en función de la acumulación neoliberal custodiada por los Estados nacionales.

Ante todo, como apuntan Leresche \& Saéz (2001), el régimen fronterizo debe basarse, dentro del marco de objetivos y principios democráticamente aceptados, en la flexibilidad y la vocación "adhocrática" de instituciones y normas. Lo que resulta la única posibilidad de afrontar la incertidumbre que corona estas regiones. En una situación en que las dimensiones y escalas de los contactos se solapan (lo local, lo nacional y lo global) es poco pertinente mantener un régimen de escalas rígidas. Como tampoco parece conveniente mantener los mismos parámetros en sociedades donde los conceptos de lo formal y lo informal, lo legal y lo ilegal, la etnia y la nación, el migrante y el visitante, se diluyen en una miríada de prácticas sociales consuetudinarias.

En consecuencia, se requiere un sistema descentralizado que otorgue a los gobiernos locales y agencias desconcentradas, atribuciones y recursos para afrontar los retos del desarrollo transfronterizo. Si algo une a las experiencias comparadas en este artículo, es el lastre de una alta centralización, que coacta el despliegue de iniciativas desde las prácticas sociales y el saber popular, y agota las mejores experiencias institucionales. Ello implicaría inevitablemente, la apertura de espacios para la participación popular y el involucramiento directo de la sociedad civil organizada. 
Por otra parte, los regímenes fronterizos dinámicos no pueden convivir exitosamente con la perspectiva que sobre el tema tienen los organismos de control, para los que la ciudadanía se define como una relación del individuo con el Estado - que ellos representan-. En cambio, están obligados a avanzar hacia otra definición que enfatice otra noción de membresía, que dé cuenta de las intensas movilidades humanas cotidianas — de las territorialidades circulatorias que resaltaba Tarrius (2000) y que conjugue razones culturales, identitarias y de relación práctica.

Por supuesto, se trata de un tema que merecería una discusión más sostenida que lo que podemos hacer en un artículo. Millones de latinoamericanos habitan en poblaciones ubicadas en contextos de fronteras, y sus vidas dependen total o parcialmente de las transacciones que en ellas se efectúan. Son poblaciones que no solo sostienen dinámicas económicas relevantes para toda la vida nacional, sino que también experimentan procesos de hibridación cultural que pudieran estar anunciando formas superiores de convivencia multicultural. En buena medida, lo que suceda con estas zonas, estas personas y sus legados, depende de cómo se organiza la gestión de los procesos desde la propia política, sus instituciones y sus normas.

\section{Bibliografía}

Agnew, John \& Oslander, Ulrich (2010) "Territorialidades superpuestas, soberanías en disputa: lección empírica desde América Latina”. Tábula Rasa, núm. 13, 191-213.

Álvarez, Camila (2019) "Entre la buena vecindad y la rígida institucionalidad transfronteriza de Arica (Chile) y Tacna (Perú)". En H. Dilla y C. Alvarez (eds.) La vuelta de todo eso: economía y sociedad en la frontera chileno/peruana: el complejo urbano transfronterizo Tacna/Arica. Santiago: Ril, 175-204.

Baud, Michiel (2000) "State Building and Borderlands". En P. van Dijck, A. Ouweneel y A. Zoomers (eds.) Fronteras: Towards a Boderless Latin America. Amsterdam: CEDLA: 41-71.

Cancillería (2013) Plan Fronteras para la prosperidad. Resumen Ejecutivo Proyecto de Inversión. Bogotá: Ministerio de Relaciones Exteriores. [En línea. URL: $<$ http://www.cancilleria.gov.co/sites/default/files/informe-ejecutivo-2013-planfronteras-la-prosperidad.pdf $>$. Consultado el 23 de enero de 2019].

Congreso de Colombia (1995) Ley de Fronteras. (Ley 191 de 1995). [En línea. URL: $<\mathrm{http}: / /$ www.aerocivil.gov.co/Aerodromos/Aeropuertos-

Transfronterizos/Documents/00-

\%20LEY\%20191\%20DE\%201995\%20FRONTERAS.pdf>. Consultado el 15 de marzo de 2018].

Constitución de la República Dominicana (2010) Gaceta Oficial, núm. 10561, del 26 de enero. [En línea. URL: <http://www.ifrc.org/docs/idrl/751ES.pdf>. Consultado el $12 \mathrm{de}$ marzo de 2018].

Constitución Política de la República de Colombia (1991) [En línea. URL: $<$ http://www.corteconstitucional.gov.co/inicio/Constitucion\%20politica $\% 20 \mathrm{de} \% 20$ Colombia\%20-\%202015.pdf>. Consultado el 23 de marzo de 2018].

Cornago, Noé (2016) "Diplomacia como heterología: pluralismo social y multiples mediaciones institucionales en la frontera". En S. González, N. Cornago y C. Ovando 
(eds.) Relaciones transfronterizas y paradiplomacia en América Latina. Santiago de Chile, Ril Editores, 17-45.

Das Neves, Alex Jorge; Baptista, Gustavo Camilo; Engel, Cíntia Liara \& Misse, Michel (orgs.) (2016) Segurança pública nas fronteiras - Sumário Executivo. Brasília: Ministério da Justiça e Cidadania.

De Jesús Cedano, Sobeida (2007) “El régimen jurídico de la frontera”. En H. Dilla y S. de Jesús (eds.) Frontera en Transición. Santo Domingo: Ciudades y Fronteras, 177-200.

Dilla, Haroldo (2015) "Los complejos urbanos transfronterizos en América Latina". Revista de Estudios Fronterizos, Nueva Epoca, vol. 16, núm. 31, 15-38.

Dilla, Haroldo (2016) "La regionalización precaria en la frontera dominico/haitiana". Si Somos Americanos, Revista de Estudios Transfronterizos, vol. XVI, núm. 1, 15-41.

Dilla, Haroldo \& Hansen, Karen (2019) “El régimen político fronterizo en Arica: más allá de la garita”. En H. Dilla y C. Alvarez (eds.) La vuelta de todo eso: economía y sociedad en la frontera chileno/peruana: el complejo urbano transfronterizo Tacna/Arica. Santiago: Ril, 153-174.

Domínguez, Jorge (ed.) (2003) Conflictos territoriales y democracia en América Latina. Buenos Aires: Siglo XXI.

Donnan, Hastings \& Wilson, Thomas M. (1999) Borders: Frontiers of Identity, Nation and State, New York: Berg.

Foucault, Michel (2003) Vigilar y castigar. México: Siglo XXI Editores.

Frei Montalva, Eduardo (1966) "Mensaje presidencial del 15 de Marzo de 1966". En http://www.bcn.cl. [En línea. URL: <http://www.bcn.cl/historiadelaley/nc/historia-de-laley/vista-expandida/4141/\#h2_1_1>. Consultado el 30 de abril de 2018].

Hurtado, Adriana \& Aponte, Jorge (2017) “¿Hacia un gobierno transfronterizo?: explorando la institucionalidad para la integración colombo-peruana”. Estudios Fronterizos, vol. 18, núm. 35, 70-89.

Jessop, Bob (2001) “The Political Economy of Scale”. En M. Perkman y N. Ling Sum (eds.) Globalization, Regionalization and Cross Border Regions. London: Palgrave, 25-49.

Kearney, Michael (2003) "Fronteras y límites del Estado y el Yo al final del imperio". Alteridades, vol. 13, núm. 25, 47-62.

Lefebvre, Henri (2013) La producción del espacio. Madrid: Capitán Swing.

Leresche, Jean-Philippe \& Saez, Guy (2001) "Political Frontiers Regimes: Towards CrossBorder Governance?”. En M. Perkman y N. Ling Sum (eds.) Globalization, Regionalization and Cross Border Regions. London: Palgrave, 77-98.

Leyton, Cristian M. (2011) Chile y Perú: una rivalidad duradera. Santiago: Ediciones Akhilleus.

Machado de Oliveira, Tito C. (ed.) (2005) Território sem limites: estudos sobre fronteiras. Campo Grande: Ed. UFMS.

Mantilla, Silvia Cristina \& Chacón Herrera, Christian (2016) "Balance comparativo de la normatividad sobre fronteras en cuatro países colindantes del Caribe". Estudios Fronterizos, vol. 17, núm. 34, 1-20.

Mateo, Andrés (2004) Mito y cultura en la era de Trujillo. Santo Domingo: Editorial Manatí. Mezzadra, Sandro \& Neilson, Brett (2013) Border as Method, or, the Multiplication of Labor. Durham and London: Duke University Press.

MINREL (2017) Dirección Nacional de Fronteras y Límites del Estado [En línea en Ministerio de Relaciones Exteriores de Chile. URL: 
$<$ http://www.minrel.gov.cl/minrel/site/artic/20080620/pags/20080620155158.html>. Consultado el 30 de octubre de 2018].

Moisio, Sami \& Paasi, Anssi (2013) "Beyond State-Centricity: Geopolitics of Changing State Spaces”. Geopolitics, vol. 18, núm. 2, 255-266 DOI: 10.1080/14650045.2012.738729.

Molano Rojas, Andrés (2016) Las fronteras en Colombia como zonas estratégicas: análisis y perspectivas. Bogotá: Instituto de Ciencia Política Hernán Echavarría Olózaga.

Morin, Edgard (2000) Sociología. Madrid: Tecnos.

Newman, David (1999) "Geopolitics Renaissant: Territory, Sovereignty and the World Poltical Map". En D. Newman (ed.) Boundary, Territory and Postmodernity. London: Frank Cass, 1-17.

Newman, David (2003) “On borders and power: A theoretical framework". Journal of Borderlands Studies, vol. 18, núm. 1, 13-25 DOI: 10.1080/08865655.2003.9695598.

Nweihed, Kaldone (1990) Frontera y límite en su marco mundial. Caracas: Equinoccio.

Oddone, Nahuel \& Galantini, Eduardo Leonel (2015) "Por la triple frontera más austral de América: un recorrido por Monte Caseros, Bella Unión y Barra do Quaraí”. En M. Barajas, P. Wong y N. Oddone (ed.) Fronteras y procesos de integración regional. México, Juan Pablos Editor, 333-355.

Oddone, Nahuel; Quiroga Barrera Oro, Martín; Sartori de Almeida Prado, Henrique \& Williner, Alicia (2016) Pactos territoriales en la construcción de regiones transfronterizas: por una mayor integración a múltiples niveles (CEPAL - Serie Desarrollo Territorial, núm 20). México: ILPES/CEPAL.

Oliveras, Xavier; Durà, Antoni \& Perkman, Marcus (2010) "Las regiones transfronterizas: balance de la regionalización de la cooperación transfronteriza de Europa". Documents d`Análisi Geografica, vol. 56, núm. 1, 21-40.

Ovando, Cristian \& Álvarez, Gonzalo (2011) "La dimensión fronteriza de la política exterior de Chile: inmovilidad y emergencia de nuevas dinámicas". Estudios Fronterizos, Nueva época, vol. 12, núm. 24, 75-102.

Perkman, Marcus (2003) “Cross-Border Regions in Europe". European Urban and Regional Studies, vol. 10, núm. 2, 153-171.

Prescott, John R. V. (1987) Political Frontiers and Boundaries. New Yok: Routledge.

Ramírez, Socorro (2007) "Las zonas de integración fronteriza: desafíos de la Comunidad Andina y Suramericana". En La integración y el desarrollo social fronterizo (Serie integración social y fronteras, No 1). Bogotá: CAB, 51-95.

Rosière, Stéphane \& Jones, Reece (2012) "Teichopolitics: Re-considering Globalisation Through the Role of Walls and Fences”. Geopolitics, vol. 17, núm. 1, 217-234.

Santis, Hernán (1998) "El pensamiento geográfico de Ratzel en la geopolítica chilena”. Revista de Geografia Norte Grande, núm. 25, 135-140.

Sassen, Saskia (2010) Territorios, autoridad y derechos: de los ensamblajes medievales a los ensamblajes globales. Buenos Aires: Katz.

Silva, Verónica \& Morán, Carlos (2010) "Relaciones subnacionales. El caso de Chile y Argentina". En L. Maira (ed.) La politica internacional subnacional en América Latina. Buenos Aires: Ediciones del Zorzal, 259-303.

Sohn, Christophe (2014) "Modelling Cross-Border Integration: The Role of Borders as a Resource”. Geopolitics, vol. 19, núm. 3, 587-608 DOI: 10.1080/14650045.2014.913029.

SUBDERE (2013) Metodología para la identificación de localidades en condición de aislamiento. Santiago de Chile: Subsercretaría de Desarrollo Regional y Administrativo, División de Políticas y Estudios, Departamento de Estudios y Evaluaciones, Unidad de 
Análisi Territorial. [En línea. URL: $<\mathrm{http}$ ://www.subdere.gov.cl/sites/default/files/documentos/metodologia_03072013.pdf> . Consultado el 23 de junio de 2018].

Tarrius, Alain (2000) "Las circulaciones migratorias: conveniencia de la noción de territorio circulatorio”. Relaciones 83, vol. XXI, 39-66.

Valenciano, Eugenio O. (1990) Los Comités de Frontera: funcionamiento y experiencia. Identificación, preparación y evaluación de proyectos de integración fronteriza. Santiago de Chile: INTAL, 40-46.

Velasco, Laura (2001) "Un acercamiento al método tipológico en sociología”. En M. L. Tarrés (ed.) Observar, escuchar, comprender: sobre la tradición cualitativa en la investigación social. México: Porrúa / El Colegio de México / FLACSO, 289-326.

Vieira Posada, Édgard \& Ramírez Vargas, Socorro (2004) Desarrollo transfronterizo e integración andina: escenarios para Colombia. Bogotá: FESCOL. 